lukewarm water), nor have $I$ ever used any of the vaunted intestinal antiseptics, never having had a high temperature or other complications which did not respond to salad oil except in two cases. The first was that of a boy with hæmorribage whose father and mother were always drunk and neglected him diggracefully. The second was a case of mitral stenosis which came under my care in a late stage of the diserase. The patients in both cases ultimately recovered.

Listly I would say that there seems to be no danger in conscientiously palpating and percussing the abdomen for the first week of the disease, and it is a valuable aid in ertimating the disappearance of accumulations, though the temperature and general bien.être of the patient are now my asual guides.

Salad oll, one pint by the mouth and half a pint per rectum, has also given the most gratifying results in two cases of typhlitis under my care.

Fremantie, Western Australia.

\section{SYPHILIS AS A CURE.}

\section{Bx d. ROSS MACMAHON, M.B., C.M. AbGRD.}

THE above heading is somewhat paradoxical. We are gccustomed to see and hear of syphilis in any other light than that of a cure. The following extraordinary and interesting case, however, manifests syphilis as a beneficent evil and although the curative element is dearly bought and the practical value little such is its academic interest that it is well worthy of record.

The case was that of a young man who had suffered from a patch of lupus valgaris non-exedens since his eighteenth year. H $\rightarrow$ had resorted to various methods of treatment under different medical men, but receiving no lasting benefit be substituted nonchalance for remedies. In his twentyseventh year he contracted syphilis, developing in turn Hunteri chancre, bubo, sore throat, slight roseola, \&s., and underwent mercurial treatment for two months. With the exception of occasional sores inside the mouth and silght dobility nothing further accrued from the Eyphilis until the time I saw him. He came to me in March of this year and complained of sores on his Ifft cheek spreading towards the lupus patch and slight]y encrozching on the same. Towards the middle of the left cheek an irregularly oval patch of lupus vulgaris was to be seen with its long axis more or less parallel with the horizontal ramus of the lower jaw ; it measured about Zitin. in long diameter and $1 \frac{1}{2}$ in. in short diameter, with s mall outstanding patch on either side stationed abreast. The pateh was of a uniformly pinkish-red colour studded wll over witin apple-jelly nodules, but more especially so at the mirgia. There was no sign of breaking down or ulceration, but at one end was a small area in which the disease hat dista,peared and left some uneven scarring. Spreading over this in a fan-shaped tashion was the adrancing crescentio ulcerating edge of a deep serpiginous syphilide. The syphilide appeared to have commenced in a broken. Gown nodule on the skin over the middle of the horizontal rarnas and to have spread in a generally circular manner comn the neck and over the cheek, leaving a pinkish white fuintly pigmented scar. The pigmentation was more of a light brown motiling, the cicatrix was dense and tolerably even. When seen it had just invaded the lupus area and appeured likely to travel right over it.

Un $m y$ advice the patient refrained from general treatment ard I contented myselt with applying mercurial plaster to the advancing edge on the neck. Cheekwards the disease advanced with some rapidity, mingling with the tiasue of the iupus patch, the two combining to form ulceraGion which involved the whole depth of skin well down to the cubcutaneous tissue. The skin on the lupus area broke down very readily on the approach of the syphilide, forming exisnsive ulceration. The edge of the ulcer was irregular abd shreddy, not characterised by the punched-out steep onge of the syphilide per se, but marked by an anmethodical oroding ; the base was foul, sloughing, reddish-grey in colour, :

In the course of a week or ten days the ulceration had ran over the graster extent of the patch, travelling most ragidly towards the left nowtril. With the local application of iodoform ointment I now prescribed mercury internally, whereat the ulcerating process at once began to abate its fury, slowly at first, and only stopped when it had involved the whole lupus area, save the upper of the two small patches. Gradually increasing the mercury and after a few days adding small doses of iodide of potassium the base of the ulcer sloughed away, a healing edge began to encroach on the raw surface, granulation sprang up, and repair slowly went on to a close. In about eight or nine weeks a large purplish-brown cicatrix formed almost level with the surrounding skin, uniform and tolerably regular, and nothing remained of the lupus area except the small outstanding patch composed of a few lupomata and one or two nodules of the upper edge of the large patch which had escaped the ravages of the syphilide. To these I applied the galvanocautery very thoroughly and dressed with a mild mercurial ointment. Shortly afterwards the patient went to sea.

In about three months I saw him again. The cicatrix over the lupus area had lost much of its pigmentation and had begun to assume a more purplish-white colour. Only one or two nodules of Iupus were visible on the patch I burnt and to these I again applied the cautery. As a whole the scar is not very disfiguring, and to the patient is much less objectionable than the lupus with the risk of its progressive increase and disfigurement. Blackbeath.

\section{Clinital âdotes:}

MEDICAL, SURGICAL, OBSTETRICAL, AND THERAPEUTICAL.

\section{"CONGENITAL ABSENCE OR DELAYED DEVELOP- MENT OF THE PATELLA." \\ By Harold N. MaYer, M D. Chicago.}

IN an article in THE LANCET under the above heading Mr. E. Muirhead Little ${ }^{1}$ gave a summary of the recorded cases of absence of the patella with the extraordinary signs of degeneracy commonly associated with this condition. Dr. A. H. Burgess ${ }^{2}$ has also described a case in which this bone was congenitally absent and which was associated with marked signs of degeneracy. There is at present in the infirmary on the poor farm in Chicago an individual who has congenital absence of the patella associated with most extraordinary stigmata of degeneration. His head, which is large, is decidedly asymmetrical, the left half of the face being somewhat larger than the right. The skull is exceedingly irregular in its osseous conformation. Both ears are very small and irregular and the ordinary auricular markings are not very apparent. There is microphthalmus of the right eye with apparently congenital haziness of the cornea. Most of the teeth have been lost but the dental arches are well formed. The arm and forearm are fairly well developed but each thumb is broad and both thumb-nails have a central groove. There is a rudimentary finger on each hand. Over the lower end of the sacrum is a fold of skin which rises somewhat above the surrounding level and conceals a slight opening in which a probe can be passed for abont a depth of one-fourth of an inch. The testicles are undescended. The thighs are well formed with the exception of the absence of the patella. The knees are not in the position of byperextension figured in Mr. Muirhead Little's article, but there is a certain amount of permanent flexion and the patient walks with them at nearly a right angle with the thigh. The feet are turned inward, so that if the leg were extended and he were standing upright pressure would be made directly upon the outer side of the foot. In the position in which he commonly moves, with the body bent upon the thighs and the legs flexed upon the thighs, he brings the soles of the feet in this position nearly parallel with a flat surface.

The individual is an imbecile and was exhibited at one time as part of a show under the title of the "Bear-Man,"

1 The LaNCET, Sept. 25th, 1897, p. 781.

2 Tre LanckT, Oct. 2nd, 1897 , p. 880. 